\title{
Is it Rational to Reject Expert Consensus?
}

\author{
Bryan Frances
}

Forthcoming, International Journal for the Study of Skepticism

Philosophers defend, and often believe, controversial philosophical claims. Since they aren't clueless, they are usually aware that their views are controversial-on some occasions, the views are definitely in the minority amongst the relevant specialist-experts. In addition, most philosophers are aware that they are not God's gift to philosophy, since they admit their ability to track truth in philosophy is not extraordinary compared to that of other philosophers. In this paper I argue that in many real-life cases, such beliefs in controversial claims are irrational. This means that most philosophers have irrational philosophical beliefs.

Sixteen years ago Thomas Kelly (2005) and I (2005a, 2005b) started the epistemology of disagreement trend, with Richard Feldman (2006, 2007), David Christensen (2007), and Adam Elga (2007) quickly adding to the mix. The peer disagreement problem quickly came to dominate the discussion. However, there are other fascinating issues to investigate regarding the epistemology of disagreement. One that has yet to garner explicit treatment is the epistemology of recognized rejection of expert consensus. My goals are to describe the scenario as it shows up in the particular subject area of philosophy, articulate and motivate the primary epistemological questions to ask regarding the scenario, and go a long way in answering them. Throughout the paper, real-life issues are paramount, as I'm analyzing a real-world set of circumstances. So, there is little evaluation of philosophical principles.

\section{The Awareness of Minority Status}

Suppose you were a professional dietician. After due investigation you think the kind of chocolate found in most candy bars causes schizophrenia. By 'due investigation' I mean that other professional dieticians would say that you had done a thorough, entirely professionally acceptable job at investigation. And then you find out via a survey of those dieticians that $18 \%$ agree with you, $71 \%$ disagree with you, and the remainder neither agree nor disagree for a variety of reasons (e.g., some say the question is ill-formed, yet others say the evidence is inconclusive, etc.).

In the philosophical analogues to this case, if you knew that you had some key evidence that the nonagreeing specialist-experts lacked, then it might be reasonable for you to stick with your view in the face of the survey facts. ${ }^{1}$ (Then again, what makes you think they don't have some key evidence you lack?) Or if you thought that there are no philosophical specialist-experts. Or if you admitted that there are philosophical specialist-experts but the percentage who agree with you is of no epistemic significance. Or

\footnotetext{
${ }^{1}$ One might think that there are no experts in philosophy, at least in the relevant sense. I use 'specialistexpert' and make no assumptions as two the epistemic status of "philosophical expertise". See Licon 2012 and Williamson 2011 for opposing views on philosophical expertise.
} 
if you knew that you were much, much more intelligent than they were. Or if you knew that a large majority of the non-agreeing specialist-experts were the victims of some horrible bias that had ruined their evaluation of the issue in question. Or if you knew that the sample size of specialist-experts was tiny (seven, say). Or if you knew that there was some selection effect in your field that misleadingly generates an incredible number of non-agreeing specialist-experts. Or if you knew that there was just one nonagreeing expert and he cloned himself a few thousand times just to manipulate the percentages of specialist-experts who agree with him. Or if you knew that there used to be $90 \%$ agreement on your view but there was a virus that killed off almost all of the agreeing specialist-experts but none of the nonagreeing ones. I will be considering some of the more realistic options below.

But if you don't know or have good overall reason to believe any of those or similar facts, and you aren't allergic to reflecting on the epistemic consequences of non-agreement with large numbers and percentages of specialist-experts, then it seems that you would be unreasonable in sticking with your controversial view.

Unless you are incredibly circumspect in your philosophizing, you know that with regard to many of the philosophical issues you have opinions on, there are a great many fully competent contemporary philosophers who disagree with those opinions. In addition, the odds are significant that you hold some philosophical opinions that are definitely in the minority amongst philosophers with the relevant expertise. You might be a substance dualist, panpsychist, or panentheist. Perhaps you think determinism is true and we have no philosophically interesting kind of free will. There are skeptics, idealists, content internalists, scientific anti-realists, non-cognitivists about moral judgment, and those who accept nonclassical logic-each of which is a case of a philosopher holding an opinion that is clearly in the minority in the relevant philosophical community of specialist-experts on those topics.

By 'philosophical expert/specialist on P' I mean, close enough, professors of philosophy who have areas of specialization that cover most of the issues relevant to $P$, who have thought long and hard in evaluating $\mathrm{P}$, who have published articles closely related to $\mathrm{P}$, etc. The reader can substitute similar reasonable criteria for 'philosophical expert/specialist' and the arguments will be largely unaffected. For most philosophical Ps, I would guess that roughly $90-95 \%$ of the specialist-experts on $\mathrm{P}$ will in fact end up being philosophy professors, with postdocs making up a sizeable portion of the remaining 5-10\%. For Ps that fall squarely into a special science in which the scientists are keenly aware (and not merely acquainted with) of the relevant philosophical arguments and other materials, some specialist-experts will be scientists.

If you think about it carefully and thoroughly, you might be able to list a half-dozen views P of yours that you know satisfy the following Minority condition.

The philosophers who are specialist-experts on $\mathrm{P}$ and who reject $\mathrm{P}$ or at least lean towards rejecting $\mathrm{P}$ outnumber by a factor of about four or more the philosophers who are specialist-experts on $\mathrm{P}$ and who accept $\mathrm{P}$ or lean towards accepting $\mathrm{P}$; furthermore, there are hundreds of philosophers who have opinions on $\mathrm{P}$ and who are specialist-experts on $\mathrm{P}$ (so the four-to-one figure is significant; I will omit mention of this second conjunct in what follows).

Let us call views with that profile minority. The Minority condition is a stipulation tool for precisifying the idea that one's view is rejected by specialist consensus in philosophy. 
For instance, the 2009 PhilPapers survey included the question 'Free will: compatibilism, libertarianism, or no free will?' The libertarians and no-free-will advocates were $14 \%$ and $12 \%$ respectively while the compatibilists were at $59 \%$ (Bourget and Chalmers 2009). Those numbers provide excellent evidence of two cases of minority views (it's clear that hundreds of philosophers have opinions regarding those three views; however, there was no demand in the poll that only experts/specialists on the relevant topics vote). The PhilPapers survey has many limitations (as the authors are well aware of; Bourget and Chalmers 2010), so the precise percentages cannot be taken too seriously. But the point is that the survey provides good evidence for the modest thesis that libertarianism and free will eliminativism are minority in the sense defined above, or at least pretty close. And we hardly need a survey to know that the sense datum theory, pantheism, and the view that ghosts exist are minority views amongst the relevant specialistexperts, as just defined.

I'm considering only those cases in which a philosopher genuinely believes a philosophical claim. It's not enough that she says it's true or even says that she thinks it's true. It's undeniable that philosophical discourse is odd compared to other discourses in that we provide many of the standard signs of believing something even though we definitely don't believe it. I know several philosophers who, when push comes to shove, have no more than a vanishingly small number of philosophical beliefs (I'm one of them). That is their most considered judgment. Even so, we also know there are a great many philosophers who "genuinely believe" philosophical claims they know to be in the minority. By 'genuinely believe' I mean their attitude towards a philosophical claims such as 'Propositional belief contents fail to weakly supervene on the believer's intrinsic physical properties from physics' is pretty much the same as their attitude towards ordinary claims such as 'The Battle of Hastings took place in 1066', 'Electrons are

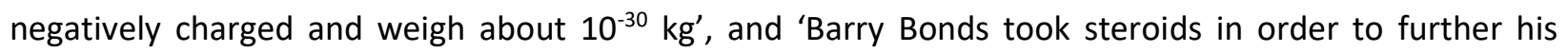
baseball accomplishments': confidently held but not extremely so.

\section{The Three Common Ways of Retaining Belief in the Face of Minority Status}

The dietician story was meant to supply a case that brings the relevant intuitions front and center. In order to proceed to the next step, it is helpful to consider an extreme case.

Jack is a climate scientist who in 2020 thinks P: there is no global warming at all. A little later he learns from a survey that S: about $97 \%$ of climate scientists currently think there is global warming. Pretend that before this he had no idea what anyone other than himself thought about the issue. How might he react to learning $S$ while retaining $P$ ?

Since this paper's topic is original, it is hard to answer that question. ${ }^{2}$ What follows are three options that apply on many occasions to philosophers when they learn that one of their views is minority in the sense defined above.

The No-process way: Jack has almost no reaction at all. He just says something non-committal such as 'Huh', and forgets about the climate scientist survey entirely: his coming to know $\mathrm{S}$ has no effect on his consciousness, as he doesn't cognitively process $\mathrm{S}$ at all. He retains his belief in $\mathrm{P}$ with no decrease in

\footnotetext{
2 Some relevant literature: Ballantyne 2019, Dellsén 2018, Goldberg 2016, Frances 2016, Frances 2018, Grundmann 2013, and Palmira 2020.
} 
confidence. For a philosopher instead of a scientist, she would probably say, in response to the awareness that her philosophical view had minority status, something utterly familiar and almost reflexive along the lines of, "Well, this is philosophy! Disagreement is the norm", and then she would not give it another moment's thought.

The Explanation way: he endorses some explanation of $S$ that allows him to be psychologically comfortable (if not epistemically reasonable) in retaining his belief in $\mathrm{P}$ with no significant change in confidence. He might think to himself that he (and perhaps others who agree with him) has some crucial bit of evidence the other climate scientists lack. Or that there is some prejudice that is greatly warping the climate community's judgment of $P$. Or that he has evaluated the common evidence better than they have, perhaps because he is a true genius compared to them. Or some other explanation. In any case, he thinks there are some "extenuating circumstances" that explain S in such a way that does not suggest that he has made a mistake in believing minority $P$.

The Moorean way, which lies halfway between the first two ways. On the one hand, it doesn't involve offering any substantive "explaining away" of $S$ (so it's different from the Explanation way); on the other hand, it does include reflection on S vis-à-vis $\mathrm{P}$ (so it's different from the No Process way). One takes the Moorean way when one thinks that $P$ is much more warranted than the premises of any argument against $\mathrm{P}$-and one thinks this even if one hasn't attempted to discover what is wrong with any such argument.

In the sections that follow I will address, in reverse order, the three ways of retaining minority P. In order to keep this essay manageable, I am not going to disambiguate 'epistemically rational' or 'epistemically reasonable' (I use them as synonyms). My essay's arguments probably go through for some but not all disambiguations. The ones most relevant to my concerns-yours may differ-are the ones that we appeal to in ordinary contexts of epistemic evaluation.

Of course, Jack might not retain $\mathrm{P}$ upon learning $\mathrm{S}$. Instead, he might come to think that there is a good chance he's missed something crucial in evaluating P. He could think that it's highly probable that the other climate scientists know something he doesn't. He might also wonder whether he did a bad job evaluating the evidence he actually had. In any case, after digesting $S$ he thinks there is a real chance $P$ is false; so he either suspends judgment entirely or at the very least drastically reduces his confidence in $\mathrm{P}$. This response is irrelevant to my purposes here, which focus on scenarios involving agents who retain $\mathrm{P}$ with no significant change in level of confidence.

\section{The Moorean way of Retaining Belief in the Face of Minority Status}

It's interesting that in some peculiar cases it appears to be epistemically rational to stick with a belief when presented with an objection to it that you admit that you can't answer at all. Unfortunately, we are about to see that what secures the rationality in these peculiar cases doesn't apply to many of the realworld minority cases under examination in this essay. 
For instance, it is easy to construct quite clever mathematical "proofs" for all sorts of obviously false claims, such as 'The sum of the positive integers is $-1 / 12^{\prime}{ }^{3}$ When faced with such pseudo-proofs, it is epistemically reasonable for people without sufficient mathematical training to stick with their old belief (or doxastic disposition) expressed by 'The sum of the positive integers isn't -1/12' even if they know they have nothing critical to say about the "proof", as they know they haven't even come close to finding any mistake in it.

This phenomenon is not restricted to mathematics: we do it in philosophy as well. For instance, most philosophers are so confident in the truth of certain claims that they will dismiss arguments against them even without any serious investigation of those arguments. If someone offers a purely philosophical and non-formal argument that I don't have a brain (e.g. an argument for compositional nihilism), well, so much for her argument: I know it's unsound-either invalid or including false premises-even before I evaluate it closely and even if my subsequent investigation fails to uncover any flaw in the argument (again, by my own lights).

Since this belief-retaining move is reminiscent of G. E. Moore's response to the basic argument for skepticism (1925), l'Il call it the Moorean move (refs; disambiguations). In more detail, here is the move.

One starts out believing $P$. One next encounters what one recognizes to be a non-formal philosophical argument $A$ against $P$. In response, one forms the belief $B$ that $P$ is much more warranted than at least one of the premises of $A$. One then retains $P$ with no change in confidence even if one admits that one has not (yet) found any flaw in $A$. This retaining of $P$ is done on the basis of $B$.

I will grant for the sake of argument that this retaining of $P$ can be epistemically reasonable if circumstances are favorable: if, for instance, $B$ is both true and well warranted.

However, I take it as relatively obvious that in the vast majority of cases in philosophy we would not be reasonable in making the Moorean move in response to discovering the minority status of one of our philosophy beliefs. The reason: it's clear that the vast majority of our minority beliefs are nowhere near as warranted as our beliefs such as 'The sum of the positive integers isn't $-1 / 12$ ', 'There are trees in North America', 'Twice two is four', etc. If you believe in sense data, idealism with respect to the external world, the epistemic conception of truth, the existence of angels, libertarianism for politics, panpsychism, or scientific anti-realism, then your belief is not going to be warranted anywhere near to the degree that a belief needs to be in order for the Moorean move to be reasonable. In other words, in cases of minority belief $B$ is false, not well-warranted, and it's obvious that it's not well-warranted.

I am not saying that the minority belief itself, before recognition of its minority status, is unreasonable. It may well be reasonable, provided that its initial basis is strong enough. That happy situation will probably be relatively rare for minority philosophy beliefs, but there is no reason to think they will be nonexistent. What I am saying above is that in the vast majority of real-life cases retaining a minority philosophical

\footnotetext{
${ }^{3}$ The example is not fictional! For discussion, see http://skullsinthestars.com/2014/01/18/infinite-seriesnot-quite-as-weird-as-some-would-say/.
} 
belief via the Moorean move won't be reasonable-and it's not reasonable because, again, B is false, not well-warranted, and it's obvious that it's not well-warranted.

In sum, the Moorean way of responding to the discovery of minority belief usually involves serious epistemic deficiency. So, don't do it.

\section{The Explanation way of Retaining Belief in the Face of Minority Status}

Let's suppose that climate scientist Jack or a philosopher with a minority view takes the Explanation way, in which he retains the belief in $\mathrm{P}$ (upon learning that $\mathrm{P}$ has Minority status) and has some substantive reaction to $S$ (where $S$ is the survey-driven belief that $P$ is a minority thesis), a reaction that starts with something along the lines of 'Yes, but you see that there are extenuating circumstances here'.

\subsection{Five Explanations of Minority Status}

As before, the literature leaves us in the dark as to the possible real-life explanations one may come to accept after learning of the minority status of one's belief P. I thought of five, any one of which may at the very least give one psychological comfort in sticking with $\mathrm{P}$.

E1. I have conclusive evidence for $\mathrm{P}$, evidence that most other philosopher specialists (especially the ones who don't agree with P) either lack, have misjudged, or had the burden of weighing against misleading contrary evidence.

E2. The philosopher specialists who are most expert on $\mathrm{P}$-the super-specialist-experts, if you willendorse my belief $\mathrm{P}$ much more than they reject it.

E3. The vast majority of philosopher specialists who appear to disagree with $\mathrm{P}$ don't really disagree with it.

E4. There is some prejudice, selection effect, bias, or similar problem that is pervasive in the relevant community of philosopher specialists and has radically warped its evaluation of $\mathrm{P}$ away from what it should be given the evidence widely available to them regarding $P$.

E5. When it comes to $P, I$ am an epistemic superior to almost all of those philosopher specialists who reject my view. Perhaps I have crucial evidence they lack. Or maybe although I don't have crucial evidence they lack, l've evaluated our common evidence much better than they have.

The difference between E1 and E5 is that in the latter one isn't saying that one has conclusive evidence. I may think that I'm your epistemic superior on certain comparative baseball claims (e.g. 'Willie Mays was better than Ralph Kiner') even though I admit that I don't have conclusive evidence for my belief.

I'm not saying that these are the only types of explanations. I suppose the reader could think of others. ${ }^{4}$ But I am confident that E1-E5 cover a large portion of actual explanations in contemporary philosophy and other, similar, intellectual affairs.

${ }^{4}$ For instance, some philosophers have a long-standing belief that even professionally considered excellent philosophical argument on behalf of $P$ virtually never amounts to significant support for $P$. If they think that they are the exception to the rule, then it's an instance of E5. But in some cases I have encountered, the philosopher thinks that his or her own philosophical arguments never amount to 
There are five good questions to ask about people who take the Explanation way, in which they think they can rationally "explain away" the fact that their view has minority status among the relevant specialists.

a. Is their explanation, E1-E5, of the belief's minority status true?

b. Is their belief in the explanation E1-E5 (epistemically) rational?

c. Is their retaining their belief in $\mathrm{P}$ on the basis of their explanation belief E1-E5 rational?

d. Is the retained belief in $\mathrm{P}$ rational?

e. Is their overall response to learning $S$ (a response which includes, as just one part, the retaining of $\mathrm{P}$ with no significant change in confidence) rational?

In the scenarios envisioned, there are three key beliefs: the original philosophical belief $P$, the explanation belief $E$ (which is one of E1-E5), and the survey belief $S$ (we will assume that before learning S one had no idea what the breakdown of specialist opinion was on P). In what follows I address questions (a)-(e), starting with the easiest one.

However, it's worth making one preliminary remark. If the survey result $\mathrm{S}$ is extreme enough-say, an incredible $99 \%$ of the thousands of polled philosopher specialists are genuinely highly confident that $P$ is false-then in most real-life circumstances one should not only give up P but any of E1-E5 as well. (In detail: in such an extreme circumstance E1 and E5 will be improbable given that one knows that one is not god-like compared to other philosophers; E2 will probably be false given the 99\% figure; E3 is false because of the use of 'genuinely highly confident'; E4 will be false for any realistically powerful bias, selection effect, etc.) But I will ignore that scenario since it is so rare in philosophy (as well as other fields). The survey result $\mathrm{S}$ will be assumed to be realistic, as in the PhilPapers results.

\subsection{The Rationality of Belief Retention}

We can start with some good news: in many cases the answer to (c) is affirmative-even if the answers to (a) and (b) are negative. To see why, consider a story.

Arif hears a bump in his house on a dark and stormy night. He has long had three cats and two dogs, and he knows through experience that nighttime bumps are usually caused by his pets; further, he has been a house owner long enough to know full well that old houses like his make all sorts of odd noises at night, pets or no, especially on stormy nights. Despite that, Arif forms an unwarranted belief: there is an intruder upstairs or downstairs. Then after searching upstairs, where his bedroom is, he learns that there is no intruder upstairs. Clearly, the reasonable thing for him to do at this point is conclude that there is an intruder downstairs-that's the perfectly reasonable cognitive move to make-despite the facts that (i) the cognitive move starts from an unwarranted belief 'There is an intruder upstairs or downstairs' and (ii) the cognitive move ends with an unwarranted belief 'There is an intruder downstairs'.

significant support for their theses, so they aren't an exception to the rule. I am uncertain what to think of these people. They seem to honestly believe their adopted positions. 
It is irrational for Arif to search upstairs for an intruder-the action is irrational. But when he discovers that there is no intruder upstairs, it is rational for him to infer that the intruder is downstairs-even though the inferred belief is irrational. So, the action is irrational, the inference is rational, and the belief at the end of the inference is irrational.

Somewhat similarly, suppose you start with beliefs $\mathrm{P}$ and E1, the latter your belief that you have conclusive evidence for $\mathrm{P}$, evidence that most other philosopher specialists either lack, have misjudged, or had the burden of weighing against misleading contrary evidence. Suppose further that your belief in E1 is false and epistemically irrational; so, the answers to (a) and (b) are negative. Later you acquire the survey belief $S$. If you react to learning $S$ by next retaining your belief in $\mathrm{P}$ partly on the basis of $\mathrm{E} 1$, well, that seems a rational cognitive move to make. Yes, you started out with an irrational belief E1, but given that you already had that belief, subsequently retaining $\mathrm{P}$ in the face of learning $\mathrm{S}$ is reasonable, as you have not encountered any new good reason to give up your belief in $\mathrm{P}$ (and nothing else appropriately epistemic has happened). Your retained belief in P might not be rational (as its status depends on additional factors such as its original basis, which is still operative), but your retaining of $\mathrm{P}$ is.

I think the same result holds if we swap E2, E3, or E5 for E1: one can obtain those beliefs before one obtains the survey belief $S$, and the above reasoning shows that the retaining of belief in $P$ (not: the retained belief in $\mathrm{P}$ itself) on the basis of those Es can be rational even if the belief in the $\mathrm{E}$ in question is false and irrational.

Matters are more complicated with E4 'There is some prejudice, selection effect, bias, or similar problem that is pervasive in the relevant community of philosopher specialists and has radically warped its evaluation of $\mathrm{P}$ away from what it should be given the evidence widely available to them regarding $\mathrm{P}^{\prime}$. One cannot believe E4 before one learns $S$, as we are assuming that before learning $S$ one had no idea what the breakdown of philosophical opinion was on $\mathrm{P}$ (more on this point below).

So, suppose one starts out believing $P$, next learns the survey result $S$, then comes to believe $E 4$, and then partly on the basis of E4 retains $\mathrm{P}$. Question (c) says: will the retaining of $\mathrm{P}$ be rational?

The same answer applies here as above: it may be the case that one's belief P started out irrational, and coming to accept E4 might be irrational as well, but given that one ended up with those two beliefs, retaining $P$ after learning $S$ is the rational cognitive move to make. What is more interesting is the question of whether the acquiring of E4 was rational. If one already had excellent evidence that there were many selection effects, prejudices, and biases that had warped many positions in the philosophical subfield in which $\mathrm{P}$ has its home, then the acquiring of E4-which focuses on $\mathrm{P}$ alone-could well be reasonable. On the other hand, if the only reason that one came to endorse E4 was $S$, then the odds are that the obtaining of E4 was irrational. In most realistic cases, in order to rationally acquire belief in E4 one needs evidence other than that supplied by beliefs in $\mathrm{P}$ and $\mathrm{S}$.

But not in all realistic cases. One might be so confident in P's truth that one is almost horrified to learn S. In one's horror, one casts around for an explanation of S. One's self-knowledge precludes believing either E1 or E5; one's knowledge of the profession rules out accepting E2 or E3. One could very well end up guessing that the truth must lie in E4, which one next observes is antecedently not terribly unlikely 
anyway, given (one's belief that) there are lots of selection effects in philosophy. So, one comes to accept E4.

In this scenario I think coming to believe E4 is rational given that one is incredibly confident in $\mathrm{P}$ to begin with. And retaining $\mathrm{P}$, on the basis of the realization that $\mathrm{E} 4$ is antecedently not terribly unlikely, is rational as well. However, the odds are very slim that one's initial very high confidence in $\mathrm{P}$ was reasonable: remember, $\mathrm{P}$ is minority. Hence, one's overall position on $\mathrm{P}$ is epistemically significantly flawed.

So much for (c): although in many cases the answer to (c) is 'yes', there are many cases in which the answer is 'no'.

\subsection{The Truth and Rationality of Explanations of Minority Status}

In this section there are ten issues to explore: the truth and rationality of the subject's beliefs in any of E1-E5 (i.e., questions (a) and (b) from section (4a) applied to each of E1-E5). I will treat E1-E5 in order.

Imagine a large group of philosophers each with just one minority view, where there are many minority views to choose from. How often do they have conclusive evidence for their minority view - minority by a four-to-one ratio-even though most other philosophers with the relevant expertise and specialization either don't have that evidence, have misjudged it, or have been afflicted with misleading evidence that our believer in $\mathrm{P}$ has somehow avoided? I think this happens on occasion, but I know of no reason to think it happens frequently. So, E1, 'I have conclusive evidence for $\mathrm{P}$, evidence that most other philosopher specialists (especially the ones who don't agree with P) either lack, or have misjudged, or have had the burden of weighing against misleading contrary evidence', is rarely true. And since this fact should be pretty obvious to a professional philosopher, it would be unreasonable for most of us to believe E1.

So, E1 is usually false and we usually have no good reason to think it's true-in the real world.

Explanation E2, that the super-expert philosophers really endorse minority $\mathrm{P}$, is rarely true as well-and this fact should be obvious to most philosophers as well. (I'm not even addressing the thorny issue of how to determine who is a "super-expert".) There are cases in which it's true, or close to being true. For instance, it's arguably true today for epistemicism for vagueness. I acknowledge that there will be an interesting number of cases in which there is something at least approaching consensus amongst the super-specialist-experts regarding a claim that garners no such consensus in the relevant community of specialist-experts.

But keep in mind what E2 requires: a situation in which there are many philosophical Ps such that around $70-80 \%$ of the super-specialist-experts on $\mathrm{P}$ endorse it while not only does $\mathrm{P}$ lack consensus amongst specialist-experts in general but is in the minority, with perhaps just 15 or $20 \%$ support amongst specialistexperts in general. That's what E2 requires in order to have consequential application. But surely that is a rare circumstance.

Just to be clear: I am not saying that it's rare that $70-80 \%$ of super-specialist-experts believe $P$ while $P$ is in the minority for the group of professional philosophers. I don't think that's rare. What I am saying is rare is what E2 demands: $70-80 \%$ of super-specialist-experts believe $\mathrm{P}$ while $\mathrm{P}$ is in the minority for the group of professional philosophers with the relevant expertise. The opinions of specialist-experts and 
super-specialist-experts are usually not that radically divergent. And we almost never have much reason to think there is such divergence.

So, E2 is usually false and we usually have no good reason to think it's true.

Explanation E3, that the philosopher specialists who say $\mathrm{P}$ is false don't really reject it, is false in many cases, as per my assumption made earlier regarding genuine belief and disagreement in philosophy. ${ }^{5}$ Moreover, I think that with regard to most minority views, most philosophers are in a position to know that philosophical specialist-experts who say $\mathrm{P}$ is false are expressing genuine beliefs regarding $\mathrm{P}$.

It might be the case that it's prevalent in philosophy that the amount of genuine belief regarding a philosophical proposition is low. That might be true because once philosophers recognize that a philosophical proposition is controversial, many of them neither believe nor disbelieve it even if they take sides in print and discussion. For the sake of argument, I will accept those ideas (which are quite plausible). But even so, it's clear that when it comes to minority philosophical claims, many philosophers do go all the way to genuine disbelief in the minority claim, as they recognize that the degree of controversy is comparatively quite low.

So, E3 is usually false and we usually have no good reason to think it's true.

Matters are more complicated with E4, the claim 'There is some prejudice, selection effect, bias, or similar problem that is pervasive in the relevant community of philosopher specialists and has radically warped its evaluation of $\mathrm{P}$ away from what it should be given the evidence widely available to them regarding $\mathrm{P}^{\prime}$.

I suppose there are all sorts of selection effects in philosophy. For instance, there is a selection effect in the philosophy of religion community: the reason why the percentage of them are theists is so high compared to that for philosophy professors in general is not anything remotely like this: a representative cross-section of philosophers were agnostics, ventured into the subfield, found the arguments for theism persuasive, and then became theists. Instead, a large percentage of them went into the field because they were already theists, virtually always Christian and quite confident in their theism, and were often keen to defend their religious views with philosophical arguments. There are probably many cases of similar selection effects in philosophy.

However, what is relevant here is a particular subset of the class of such effects: how often is it true that a selection or similar effect is so strong that it makes the relevant philosophical community of specialists reject $P$ by roughly four to one when the evidence widely available to those specialists is actually in favor of $P$ ? That is exactly what it takes for $E 4$ to be true.

Intuitively, E4 happens rarely. For a supporting argument, think of the consequences of E4 being true in a significant percentage of cases. To make things simple, imagine that ten philosophers have five minority philosophical views each and many of the views are distinct, so there are 30 minority views total (so there is a realistic amount of overlap in minority views amongst those ten philosophers). Suppose further that

\footnotetext{
${ }^{5}$ Of course, there are many cases in which philosophers discover that they don't really disagree-and the discovery is not easy. But, again, in this essay I'm looking at the cases in which philosophers really do disagree.
} 
contrary to one would expect E4 is true for half of the 30 minority propositions. On the face of it, this looks like a good thing for those ten people since in half of the 30 cases the person in question endorses $\mathrm{P}, \mathrm{P}$ is genuinely the right thing to believe given the widely available evidence, and the fact that $\mathrm{P}$ has minority status is the result of some epistemically bad thing infecting the philosophical community.

However, if the latter bit is true, regarding the bad infection in philosophy, then it looks as though the philosophical community is epistemically terrible, as it keeps wildly screwing up its evaluation of the widely available evidence-and this happens many times ( $50 \%$ of the time in this scenario). And if the community keeps misevaluating the widely available evidence, as assumed, then how is it plausible that those ten people-average philosophers, not geniuses-managed to judge P well on the widely available evidence in the first place, given the pervasive evidence misevaluation in the philosophical community? The lesson is peculiar: the more often E4 is true, the less often it can be that minority views are reasonable!

That was an argument about the frequency of E4's truth-value: E4 is rarely true. But how often is belief in E4 reasonable? That is, how often do we have good reason to think that a selection or similar effect is so strong that it makes the relevant philosophical community of specialists reject $\mathrm{P}$ by roughly four to one when the widely available evidence is actually in favor of P? I don't have an argument, but it strikes me that we rarely have such reason. (Finding a couple examples will obviously not suffice.) I will not comment further on $\mathrm{E} 4 .^{6}$

So, E4 is usually false and we usually have no good reason to think it's true.

When it comes to $E 5$, which says that when it comes to $\mathrm{P}, \mathrm{I}$ am an epistemic superior to almost all of those philosopher specialists who reject my view, we have to carefully attend to what it really says. Compare two claims, with the relevant difference highlighted.

E5. When it comes to $\mathrm{P}, \mathrm{I}$ am an epistemic superior to almost all of those philosopher specialists who reject my view.

E5'. When it comes to P, I am an epistemic superior to almost all of those philosophers who reject my view.

E5' is probably true in a significant percentage of cases. For instance, I might be a philosopher of language who after years of research thinks P: there are sharp cutoffs in meaning for most declarative sentences of natural languages. I know that such a view is unpopular amongst philosophers in general. But I'm not bothered by that sociological fact because I know that most philosophers have little familiarity with the considerations relevant to P (as they don't have a deep understanding of the problems of vagueness). I'm hardly guilty of excessive self-confidence in thinking that I'm the epistemic superior of the vast majority of philosophers in general who reject $\mathrm{P}$.

But it's much less common that I will be the epistemic superior of the vast majority of the relevant philosopher specialists who reject P. Remember that there are at least roughly four times as many who

\footnotetext{
${ }^{6}$ Philosophers have recently done work on biases and selection effects, although most of them have to do observation and other issues only tangential to ours (e.g. Bostrom 2012, Siegel 2013, Saul 2013). By my lights, the research does not support the idea that E4 is often true.
} 
reject or lean towards rejecting my belief $\mathrm{P}$ as who accept or lean towards accepting it. That suggests that E5 is rarely true.

However, matters are more complicated than the previous paragraph suggests! For instance, although I may readily admit that many specialists who don't accept $P$ are better overall philosophers than I am - no matter how we spell out 'better overall philosopher' $-I$ may think I'm their epistemic superior on $P$, on that one specific issue. I may think I'm your superior on $\mathrm{P}$ in virtue of the fact that despite my overall average-philosopher status I have a fantastic but as yet unknown or significantly misunderstood or underappreciated argument for $\mathrm{P}$-or I have avoided some epistemic defect that has infected your evaluation of $P$.

In these situations, a philosopher knows she has minority view $\mathrm{P}$ but also believes that she is the epistemic superior regarding $\mathrm{P}$ of almost all of the many philosopher specialists (not: philosophers in general) who reject $\mathrm{P}$ or lean towards rejecting it-even though she realizes that she is not the epistemic superior of those philosopher specialists regarding philosophical evaluation in general or even in the subfield in question. I take it that there are many actual instances of this situation. For instance, a philosopher of mind accepts hylomorphism even though he's well aware that despite his superiority on hylomorphism he's not God's gift to philosophy, the philosophy of mind, or even the metaphysics of mind.

Hence, I can accept that E5 is occasionally true: sometimes a philosopher knows her philosophical thesis $\mathrm{P}$ is a minority one but insists-correctly! - that she is an epistemic superior, regarding $\mathrm{P}$, to almost all the philosopher specialists who reject or lean towards rejecting P. But how often is it true in the real world? That is, given a philosopher who believes a view $\mathrm{P}$ such that about four times as many philosophical specialist-experts on $\mathrm{P}$ reject it as accept it, how often will it happen that she is the epistemic superior of the vast majority of those specialist-experts who reject or lean away from $\mathrm{P}$ ?

I'm not sure how to argue the point, which is about as empirical as they come in philosophy, but it seems to me that this happens rarely. For instance, when one is breaking new ground, one can be the epistemic superior of most philosopher specialists regarding one of one's new philosophical beliefs, but (i) this doesn't happen often and (ii) when it does happen, there usually isn't much genuine disagreement in the relevant philosophical specialist community, as $\mathrm{P}$ will not be believed or disbelieved often by the rest of that community (so, P won't be minority).

But that's issue (a), regarding the frequency of the truth of E5, not the issue captured with question (b): how often do philosophers who recognize themselves as having a minority view P reasonably believe E5, that they are epistemic superiors of the vast majority of philosopher specialists who reject or lean away from P? Never mind whether their beliefs in superiority-on-P are true; are they reasonable, in the ordinary sense(s) of a particular belief being epistemically 'reasonable'?

There will be cases in which the belief in superiority is as reasonable as just about any belief. The philosopher in question might not be a genius but be suffering under a significant amount of misleading evidence; assume further that she hasn't psychologically squashed any evidence against her superiorityon-P belief and has even thought the matter through in a reasonable manner. Given the odd position she is in, her false belief in superiority on P can be as reasonable as you like (just use your novel-writing skills to fill out the situational details). 
Then again, it is easy to think of highly realistic situations in which her belief in superiority won't be reasonable. Perhaps she is in thrall of her memory of being just about the smartest person in her graduate program; or maybe she is excessively impressed with her new professional status upon getting her first tenure-track position. Or she may return, again and again, in her mind to the fact that she has spent over a decade evaluating $P$, foolishly ignoring the obvious fact-which she should know - that many of the philosophers (with the appropriate expertise) who don't accept $P$ after due reflection have done the same extended, professional evaluation.

The issue of the frequency of truth and reasonable belief in $\mathrm{E} 5$ are empirical matters, and I have not even figured out how to evaluate them. For what it's worth, my own experience in philosophy suggests that in most actual cases belief in E5 is unwarranted in addition to false. However, I hope the above discussion, albeit incomplete due to the empirical nature of the issues, illuminates the relevant points.

\subsection{The Rationality of Retailed Belief and Overall Response}

There are two remaining questions to address, and to keep the discussion concise I will merely mention some of the relevant issues, without attempting any resolution.

d. Is the retained belief in $P$ rational?

e. Is their overall response to learning $S$ (a response which includes the retaining of $P$ as just one part) rational?

Regarding (d), if the belief in P started out irrational (i.e., it was irrationally held before learning S), then even if the retaining of it was rational (so the answer to (c) is 'yes'), the retained belief in $P$ will be irrational. So, the answer to (d) will be 'no' if the belief in P started out irrational.

On the other hand, if (i) the belief in $\mathrm{P}$ started out rational, and (ii) the retaining of it was rational, then in all or at least almost all real-life cases the retained belief in $\mathrm{P}$ will be rational as well. We have seen that (ii) is sometimes true. What about (i)? How often are minority philosophical beliefs rational?

That is an obviously empirical question that I cannot answer here.

Regarding (e), we can note two facts.

First, it can easily be the case that the philosopher's overall response to learning $S$ is epistemically and alethically flawed even though the both the retained minority belief and the retaining of that belief are rational. We saw this earlier with (c): even if (a) and (b) are false-so the E explanation is false and the philosopher's belief in it is irrational-it remains true that the minority belief $\mathrm{P}$ can start out rational and her retaining of it on the basis of her explanation be rational. In such a case, her reaction to the survey result $S$ is rational and yet there is some epistemically unfortunate doxastic states anyway-the false and irrational belief in $\mathrm{E}$-thereby making her overall response include serious epistemic and alethic flaws.

Second, consider a false but rational belief in epistemic superiority on $\mathrm{P}$ (e.g. sufficiently strong misleading testimony could secure this rationality). If one starts out rationally believing minority $P$ and rationally believing in one's significant superiority on $\mathrm{P}$ compared to virtually all specialists on $\mathrm{P}$-based on misleading testimony and other clues-and then learns $\mathrm{S}$, one would be rational in retaining $\mathrm{P}$ and the retained belief in $\mathrm{P}$ would be rational as well. If the belief in superiority is both held with high confidence 
and posits significant enough superiority, then it would be similar to learning that the vast majority of first-year undergraduates disagree with your philosophical belief. In such a situation it is rational to retain P. But one's overall response to $S$ is alethically flawed: it involves, in a crucial way, a false belief (in superiority on $\mathrm{P}$ ). In addition, the described scenario-with the philosopher rationally thinking that she is the clear epistemic superior to her detractors regarding $\mathrm{P}$-is probably unlikely as well.

In sum, we have answers (occasionally tentative) to the five questions about the Explanation way.

a. Is their explanation, E1-E5, of the belief's minority status true? Answer: rarely.

b. Is their belief in the explanation E1-E5 (epistemically) rational? Answer: rarely.

c. Is their retaining their belief in P on the basis of their explanation belief E1-E5 rational? Answer: often.

d. Is the retained belief in P rational? Answer: rarely.

e. Is their overall response to learning $S$ (a response which includes, as just one part, the retaining of $\mathrm{P}$ with no significant change in confidence) rational? Answer: rarely.

In sum, just like the Moorean way of responding to the discovery of minority belief, the Explanation way usually involves serious epistemic and/or alethic deficiency.

\section{The No-Process Way of Retaining Belief in the Face of Minority Status}

Let's next suppose our protagonist takes the No-Process way of responding to the survey result $S$, in which he retains the belief in $\mathrm{P}$ with no change in confidence in $\mathrm{P}$ and has no interesting reaction to learning of P's minority status. The difference between the Moorean way and the No-Process way is that only in the former does one form the disposition to think that one's belief in $\mathrm{P}$ is extremely well-warranted compared to the challenge to $P$.

On the face of it, it's unwise to not process how $\mathrm{S}$ bears on P. After all, it should be pretty clear to any philosopher that the truth of $\mathrm{S}$-the claim that the philosophers who are specialist-experts on $\mathrm{P}$ and who reject $\mathrm{P}$ or at least lean towards rejecting $\mathrm{P}$ outnumber by a factor of about four or more (!) the philosophers who are specialist-experts on $\mathrm{P}$ and who accept $\mathrm{P}$ or lean towards accepting $\mathrm{P}$-provides excellent evidence that the direction of the combination of available pro and con considerations regarding $\mathrm{P}$ is not in favor of $\mathrm{P}^{\prime} \mathrm{s}$ truth. That's to put it mildly: in fact, $\mathrm{S}$ provides strong evidence that the direction is significantly in favor of P's falsity. When faced with excellent evidence that the available evidence goes significantly against your belief, it is not very reasonable to not process that discovery (and if one does process it, then we have a case of the Explanation response or the Moorean response).

Hence, in typical cases the No-Process response involves epistemic deficiency. However, there are a couple other points that should be kept in mind.

First, as before we need to separate 'Is the retaining of belief P rational?' from 'Is the retained belief in P rational?' The answer to the latter question is largely determined by the strength of the original basis for $P$. If that basis made $P$ rational, by a considerable margin, then the epistemic $\sin$ in his no-process reaction to learning the survey result $\mathrm{S}$ might not be major enough to render the retained belief in $\mathrm{P}$ irrational 
provided the initial overall epistemic basis for $\mathrm{P}$ was overwhelming. However, the odds that minority $\mathrm{P}$ had an overwhelming original epistemic basis are low.

Second, if the philosopher genuinely thinks that $S$ is poor evidence that the available evidence is significantly against $P$, then a reasonable thing for her to do upon learning $S$ is to not think about the S-P connection and keep her belief in P. However, in this scenario she likely has a false belief, because in most cases $S$ really is excellent evidence that the available evidence is significantly against $P$. Furthermore, in most cases she should know better than to have that false belief.

Hence, her overall response to learning $\mathrm{S}$ is epistemically and perhaps alethically flawed.

\section{Results}

We started with an original question, "When you discover that a belief of yours has minority status, and you retain that belief after that discovery, is your belief retention and overall epistemic position reasonable?" Here is what we have learned.

- We saw that there are at least three common ways of retaining recognized minority belief: the No-Process, Moorean, and Explanation ways.

- The Moorean response virtually always involves serious epistemic deficiency due to the presence of a belief that is false and unwarranted.

- With respect to the Explanation way, we saw that there are at least five typical species of the Explanation genus, E1-E5.

- We also saw that there are five good questions to ask about the epistemology of those five species, questions (a)-(e) of section $4 a$.

- Finally, we saw that all five species of the Explanation way involve serious epistemic (or alethic) deficiency.

- With respect to the No-Process way, we saw that the overall response to learning $S$ is epistemically and perhaps alethically flawed.

\section{References}

Ballantyne, N. 2019. “Epistemic Trespassing," Mind 128: 367-395.

Bostrom, N. 2002. Anthropic Bias: Observation Selection Effects in Science and Philosophy (Studies in Philosophy). New York and London: Routledge.

Bourget, D. \& D. Chalmers. 2009. "PhilPapers survey," http://philpapers.org/surveys/

Bourget, D. \& D. Chalmers. 2010. "On the Conception and Design of the PhilPapers Survey," http://philpapers.org/surveys/designthoughts.html

Christensen, D. 2007. “Epistemology of Disagreement: The Good News," Philosophical Review 116: 187218. 
Dellsén, F. 2018. "When Expert Disagreement Supports the Consensus," Australasian Journal of Philosophy 96: 142-156.

Elga, A. 2007. "Reflection and Disagreement," Noûs 41: 478-502.

Feldman, R. 2006. "Epistemological Puzzles about Disagreement." In S. Hetherington (ed.), Epistemic Futures, 216-236. New York: Oxford University Press.

Feldman, R. 2007. "Reasonable Religious Disagreements." In L. Antony (ed.), Philosophers without Gods: Meditations on Atheism and the Secular Life, 194-214. New York: Oxford University Press.

Frances, B. 2018. "Philosophical Expertise." In J. Chase \& D. Cody (eds.), The Routledge Handbook of Applied Epistemology, 297-306. New York: Routledge.

Frances, B. 2016. "Worrisome Skepticism about Philosophy," Episteme 13: 289-303.

Frances, B. 2005a. "When a Skeptical Hypothesis is Live," Noûs 39: 559-95.

Frances, B. 2005b. Scepticism Comes Alive. Oxford: Oxford University Press.

Goldberg, S. 2016. “On the Epistemic Significance of Evidence You Should Have Had," Episteme 13: 449470.

Grundmann, T. 2013. "Doubts about Philosophy? The Alleged Challenge from Disagreement." In T. Henning \& D. Schweikard (eds.), Knowledge, Virtue, and Action. Essays on Putting Epistemic Virtues to Work, 72-98. New York: Routledge.

Kelly, T. 2005. "The Epistemic Significance of Disagreement." In T. Gendler and J. Hawthorne (eds.) Oxford Studies in Epistemology, vol. 1, 167-196. Oxford: Oxford University Press.

Lackey, J. \& D. Christensen (eds.). 2013. The Epistemology of Disagreement: New Essays. Oxford: Oxford University Press.

Licon, J. A. 2012. "Sceptical Thoughts on Philosophical Expertise," Logos and Episteme 3: 449-458.

Moore, G. E. 1925. “A Defence of Common Sense." In J. Muirhead (ed.), Contemporary British Philosophy (2nd series), 191-223. London: George Allen \& Unwin.

Palmira, M. 2020. "Expert Deference About the Epistemic and Its Metaepistemological Significance," Canadian Journal of Philosophy 50: 524-538.

Siegel, S. 2013. "Can Selection Effects on Experience Influence its Rational Role?” In T. Szabó Gendler \& J. Hawthorne (eds.), Oxford Studies in Epistemology 4, 240-272. Oxford: Oxford University Press.

Saul, J. 2013. "Scepticism and Implicit Bias," Disputatio v. 5: 243-263.

Warfield, T. \& R. Feldman (eds.). 2010. Disagreement. Oxford: Oxford University Press.

Williamson, T. 2011. "Philosophical Expertise and the Burden of Proof," Metaphilosophy 42: 215-229. 